УДК 599.322.2

\title{
ВОЗРАСТНАЯ СТРУКТУРА ПОПУЛЯЦИИ АЗИАТСКОГО БУРУНДУКА (TAMIAS SIBIRICUS) В СЕВЕРНОМ ПРИОХОТЬЕ
}

\author{
Дубинин $E$. А. \\ ФГБУН Институт биологических проблем Севера ДВО РАН, г. Магадан \\ E-mail: edu@ibpn.ru
}

\begin{abstract}
Исследована возрастная изменчивость степени стертости жевательной поверхности первого нижнего коренного зуба в популяции азиатского бурундука Северного Приохотья. Выявлено, что у сеголеток со времени выхода из выводковых нор до залегания в спячку индекс стертости жевательной поверхности $m_{1}$ составляет 0.6-3.5\%. У взрослых перезимовавших зверьков площадь обнажения дентина на жевательной поверхности моляра ежегодно увеличивается в среднем на 5-6\%. По индексу стертости в популяции выделяются 4-5 возрастных классов. Доминирует по численности группа зверьков возраста $1+$ лет (40.8 \%). Удельная выживаемость особей в интервале от 1 года до 3 лет равна примерно 0.5. После 3 лет она резко снижается (0.23). До 4 лет и более в популяции доживает менее 3 \% особей.
\end{abstract}

Ключевые слова: азиатский бурундук, Tamias sibiricus, возрастная структура, Северное Приохотье.

DOI: $10.34078 / 1814-0998-2021-3-90-96$

\section{ВВЕДЕНИЕ}

Азиатский бурундук (Tamias sibiricus) - один из фоновых представителей млекопитающих Северного Приохотья, где он населяет различные древесно-кустарниковые насаждения от пойм рек до подгольцового пояса сопок. Несмотря на широкое распространение и относительную многочисленность вида в рассматриваемом регионе, ряд вопросов его популяционной биологии остаются недостаточно исследованными. В частности, это относится к возрастной структуре популяции (Кищинский, 1972; Юдин и др., 1976; Чернявский, 1984; Докучаев и др., 2011), изучение которой и является основной целью данной работы. В задачи исследования входило выделение возрастных классов и описание обобщенной возрастной структуры популяции бурундука, а также ее сезонной динамики.

\section{МАТЕРИАЛ И МЕТОДЫ}

Материал был получен в ходе летних учетов мелких млекопитающих, проводившихся по стандартной методике ловушко-линий в 20112014 гг. сотрудниками лаборатории экологии млекопитающих ИБПС ДВО РАН и студентами кафедры биологии СВГУ в окрестностях г. Мага-

(C) Дубинин Е. А., 2021 дана (рис. 1). За этот период в общей сложности было отловлено 198 экз. T. sibiricus.

Каждый пойманный зверек подвергался стандартной морфометрической обработке и исследовался на предмет состояния его генеративной системы (Новиков, 1953). Определение возраста проводилось по комплексу признаков.

В частности, для разделения сеголеток и особей старше года использовали их размерно-

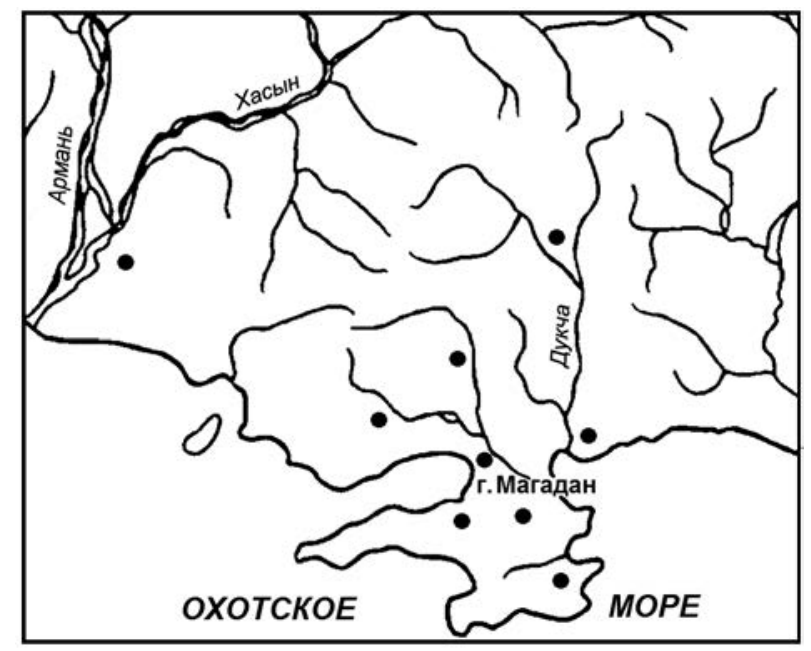

Puc. 1. Карта-схема мест сбора материала (черные кружки)

Fig. 1. Schematic map of the collection areas (black circles) 
весовые характеристики и состояние генеративной системы. Оценка возраста перезимовавших бурундуков осуществлялась по степени стертости эмали на жевательной поверхности первого коренного зуба нижней челюсти $\left(m_{l}\right)$. Это было обусловлено лучшей сохранностью нижнего зубного ряда по сравнению с таковым верхней челюсти, поскольку при отлове зверьков давилками часть черепов бывает сильно повреждена.

Осмотр зубов велся под бинокуляром МБС-10. С помощью цифровой камеры делались фотографии жевательной поверхности моляров при увеличении $16^{\times}$(рис. 2 ).

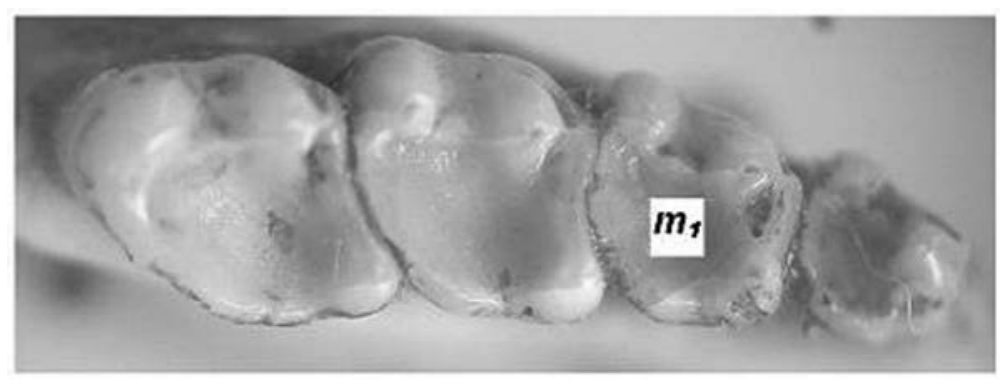

Puc. 2. Нижний зубной ряд Tamias sibiricus (увеличение: $16^{\times}$), $m_{1}-$ первый нижний коренной зуб

Fig. 2. Lower dentition of Tamias sibiricus (magnification: $16^{\times}$), $m_{1}$ - first lower molar

Затем при компьютерной обработке изображения зубов увеличивали и палеткой измеряли площадь жевательной поверхности $m_{1}$ и обнаженных участков дентина на ней.

\section{РЕЗУЛЬТАТЫ И ОБСУЖДЕНИЕ}

Молодые зверьки массово выходят на поверхность из выводковых нор во второй половине июля (Кищинский, 1972; Юдин и др., 1976; наши данные). В течение последующего месяца они заметно отличаются от взрослых особей меньшими массой и размерами тела (рис. 3).

Однако бурундучата быстро растут, и со второй половины августа они уже мало уступают по этим параметрам своим старшим собратьям. В это время более надежным показателем возраста служит состояние генеративной системы.

Puc. 3. Сезонная динамика массы тела (А) и длины туловища (Б) взрослых (ad) и сеголеток (subad) азиатского бурундука в окрестностях г. Магадана, 2011-2014 гг. Указаны среднее значение и одно среднеквадратическое отклонение от него

Fig. 3. Seasonal dynamics of the body weight (A) and body length (Б) of the Siberian chipmunk adults (ad) and subadults (subad) in the surroundings of Magadan, 20112014. The average value and one standard deviation from it are indicated
Как известно (Шубин,1965; Меженный, 1968), у взрослых бурундуков, хотя бы раз участвовавших в размножении, половые органы даже в состоянии покоя значительно крупнее, чем у еще не приступивших к размножению молодых зверьков. Так, у самок-сеголеток длина рогов матки составляет 18-20 мм, а диаметр - 1 мм. У взрослых самок эти параметры даже после размножения колеблются в пределах 22-30 и 1.2-1.8 мм соответственно, кроме того, у рожавших самок на рогах матки сохраняются хорошо заметные послеплодные пятна. Максимальные размеры семенников у самцов-сеголеток не превышают 5 мм в длину и 2.8 мм в ширину, у взрослых особей вне периода гона их минимальная длина равняется 6 мм, а ширина колеблется в пределах 3-4 мм.

На северо-западном побережье Охотского моря, в долине р. Кухтуй, размеры семенников взрослых самцов в июне составляли в среднем $8.5 \pm$ 0.5 мм в длину и $3.9 \pm 0.3$ мм в ширину, а в июле $-6.3 \pm 0.3 \times 3.2 \pm 0.2$ мм (Юдин и др., 1976). Сходные размеры семенников имеют бурундуки и в окрестностях Магадана (табл. 1).

Определить возраст зверьков, перезимовавших хотя бы один раз, по состоянию генеративной системы, размерам и массе тела уже не пред-
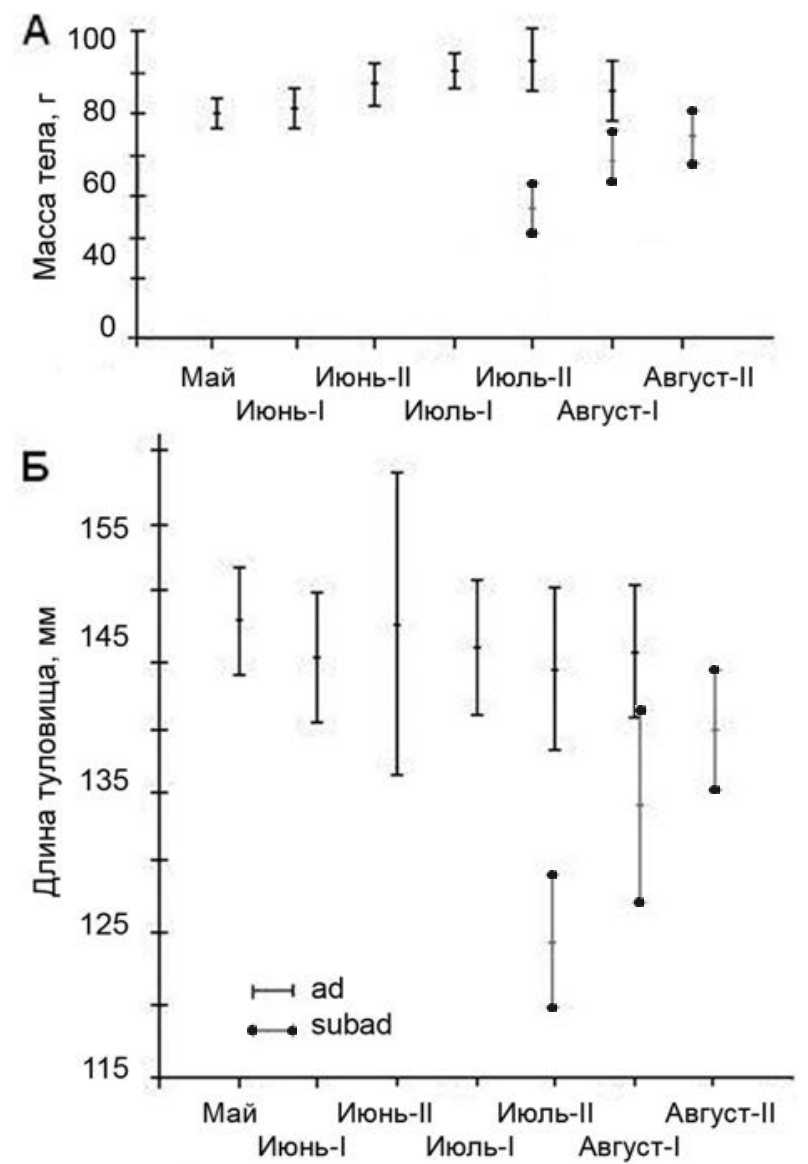
Таблица 1. Сезонная динамика относительного объема (длина $\times$ ширина, мм) семенников самцов азиатского бурундука в окрестностях г. Магадана, 2011-2014 гг.

Table 1. Seasonal dynamics of the relative volume (length $\times$ width, $\mathbf{m m}$ ) of the testes of Siberian chipmunk males of in the surroundings of Magadan, 2011-2014

\begin{tabular}{|c|c|c|}
\hline \multirow{2}{*}{ Месяц } & \multicolumn{2}{|c|}{ Возрастная группа } \\
\hline & Взрослые, $\mathrm{M} \pm \mathrm{m} / \mathrm{lim}$ & Сеголетки, $\mathrm{M} \pm \mathrm{m} / \mathrm{lim}$ \\
\hline \multirow{2}{*}{ Май $(\mathrm{n}=4$ / -) } & $18.6 \pm 1.91 \times 8.1 \pm 0.31$ & \multirow{2}{*}{-} \\
\hline & $13.5 \times 8.0-21.0 \times 9.0$ & \\
\hline \multirow{2}{*}{$\begin{array}{c}\text { Июнь, первая половина } \\
(\mathrm{n}=8 /-)\end{array}$} & $14.0 \pm 1.21 \times 6.1 \times 0.64$ & \multirow{2}{*}{-} \\
\hline & $10.0 \times 4.0-20.0 \times 7.0$ & \\
\hline \multirow{2}{*}{$\begin{array}{l}\text { Июнь, вторая половина } \\
(\mathrm{n}=14 / \text {-) }\end{array}$} & $10.6 \pm 0.99 \times 4.7 \pm 0.38$ & \multirow{2}{*}{-} \\
\hline & $7.0 \times 3.5-18.0 \times 8.0$ & \\
\hline \multirow{2}{*}{$\begin{array}{l}\text { Июль, первая половина } \\
(\mathrm{n}=14 \text { / -) }\end{array}$} & $8.4 \pm 0.35 \times 3.7 \pm 0.14$ & \multirow{2}{*}{-} \\
\hline & $7.0 \times 3.5-12.0 \times 4.0$ & \\
\hline \multirow{2}{*}{$\begin{array}{l}\text { Июль, вторая половина } \\
(\mathrm{n}=7 / 2)\end{array}$} & $7.0 \pm 0.0 \times 3.7 \pm 0.09$ & \\
\hline & $7.0 \times 3.5-7.0 \times 4.0$ & $3.0 \times 2.5-4.0 \times 2.0$ \\
\hline \multirow{2}{*}{$\begin{array}{c}\text { Август, первая половина } \\
(\mathrm{n}=1 / 7)\end{array}$} & & $\underline{4.0 \pm 0.22 \times 2.5 \pm 0.0}$ \\
\hline & $\overline{7.3 \times 3.8}$ & $3.0 \times 2.5-5.0 \times 2.5$ \\
\hline $\begin{array}{c}\text { Август, вторая половина } \\
(\mathrm{n}=-/ 3)\end{array}$ & - & $\frac{3.8 \pm 0.15 \times 2.3 \pm 0.24}{3.5 \times 1.8-4.0 \times 2.6}$ \\
\hline
\end{tabular}

Примечание. $\mathrm{n}$ - объем выборки в экз.; над чертой - количество взрослых особей, под чертой - сеголеток; прочерк означает, что особи данной возрастной группы в выборке отсутствуют.

ставляется возможным, поэтому мы воспользовались методикой оценки возраста особей по степени стертости эмали на жевательной поверхности коренных зубов. Этот метод успешно используется для определения возраста различных представителей семейства беличьих (Sciuridae), в том числе и бурундука (Кирис, 1937; Петровский, 1961; Меженный, 1964; Шубин, 1965; Шадрина, 1988; Машкин, Колесников, 1990). В частности, А. А. Меженный (1964) описал и сделал зарисовки возрастных изменений зубной системы T. sibiricus, обитающего на территории Южной Якутии. По ним можно с точностью до 1 мес определить возраст у сеголеток и с точностью до года у зверьков старшего возраста.

Как и любой метод, определение возраста по степени изношенности зубной системы имеет свои преимущества и свои недостатки. Основные преимущества этой методики заключаются в быстрой возможности разделения зверьков на возрастные группы, а также в относительной простоте. Она не требует специальной подготовки и оборудования, но ее недостатком является субъективность глазомерной оценки исследователя. Кроме того, существенный вклад в величину ошибки определения могут вносить индивидуальные особенности развития и питания животных (Егоров, 1961; Шадрина, 1988; Машкин, Колесников, 1990; Клевезаль, 2007).

Чтобы уменьшить степень субъективности глазомерной оценки и иметь возможность про- водить статистическую оценку полученных данных, Н. Г. Шубин (1965) предложил использовать индекс стертости зубов - отношение площади обнажения дентина к общей площади жевательной поверхности моляра, выраженное в процентах. Упомянутый автор по степени изношенности верхнего среднего коренного зуба в выборке из популяции бурундука в окрестностях г. Анжеро-Судженск (бассейн р. Томь, Западная Сибирь), собранной в весенний период, сразу после выхода зверьков из спячки, выделил 3 возрастные группы. В первую вошли особи, перезимовавшие один раз (т. е. в возрасте около года), с индексом стертости зубов 0.1$5.0 \%$; во вторую - зверьки, прошедшие две зимовки (в возрасте около 2 лет), у которых индекс стертости зубов варьировал от 5.1 до 9.0 \%; в третью бурундуки, перезимовавшие 3 раза и более, с индексом стертости от 9.1 до $33.3 \%$. Ввиду того, что в последней группе находилось очень мало особей, Н. Г. Шубин пришел к выводу, что дальнейшая их градация не целесообразна, так как популяция полностью обновляется за 3-4 года.

Поскольку мы не располагали эталонными образцами зубов от животных с известной датой рождения, то определение возраста по значениям индекса стертости зубов проводилось поэтапно.

Сначала был выявлен диапазон изменчивости индекса стертости жевательной поверхности $m_{1}$ у сеголеток (рис. 4). При сопоставлении этих данных с индексом стертости зубов у зверьков в весенний период годовиков отделяли от особей старшего возраста, так как за время зимней спячки заметных изменений состояния зубной системы не происходит (Шубин, 1965). В нашем случае, вследствие неравномерности распределения собранного материала по месяцам, мы можем сравнить степень стертости зубов у зверьков примерно за месяц до залегания в спячку и через месяц после выхода из нее. За эти 2 мес обнажения дентина должны развиться сильнее. Тем не менее у особей, впервые уходящих на зимовку в конце августа, и у них же на следующий год, через 1 мес после пробуждения, перекрывание значений индекса стертости зубов еще довольно велико. Так, 13 из 48 годовалых бурундуков, добытых до середины июля, имели индекс стертости зубов от 1.8 до $3.5 \%$. У се- 


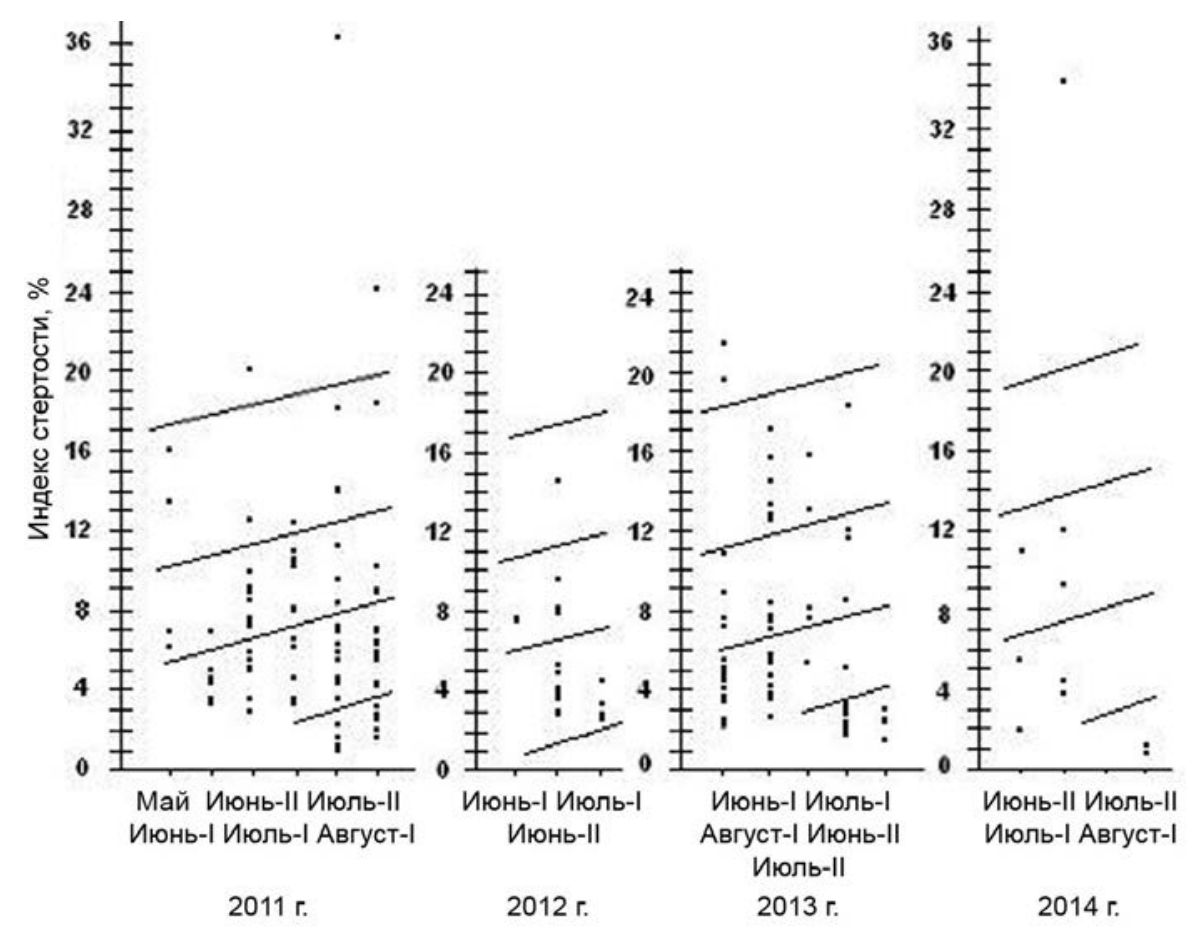

Puc. 4. Распределение особей по возрастным классам на основе индекса стертости $m_{1}$ в популяции азиатского бурундука в окрестностях г. Магадана в 2011-2014 гг. Прямыми линиями последовательно снизу вверх отделены возрастные группы: $0+, 1+, 2+, 3+, \geq 4+$ лет

Fig. 4. Age class distribution of individuals, based on the abrasion index $m_{1}$ in the Siberian chipmunk population in the surroundings of Magadan in 2011-2014. The age groups are separated by straight lines from bottom to top, sequentially: $0+, 1+, 2+, 3+, \geq 4+$ years

голеток в августе он равен 0.6-3.5 \%. Значительный разброс в степени стертости зубов уже перед первым залеганием в спячку, очевидно, обусловлен индивидуальными особенностями питания зверьков.

Если рассматривать выборку в целом и без учета времени поимки, то видно (см. рис. 4), что по индексу стертости у годовалых бурундуков зона трансгрессии существует не только с сеголетками, но и с двухлетними зверьками. Среди особей возраста 2+ лет лишь 6 экз. имели индекс стертости от 6.2 до $7.2 \%$ (остальные 38 - более $7.2 \%$ ). У годовалых бурундуков из 71 особи такие же значения индекса стертости отмечены у 8 экз., у остальных они были ниже $6.2 \%$.

Высокая индивидуальная изменчивость индекса стертости зубов ведет, как показано выше, к перекрыванию его значений между особями смежных возрастных классов. Зоны трансгрессии особенно хорошо заметны между младшими возрастными группами и не позволяют четко выделять их без учета времени сбора материала. Значения индекса стертости жевательной поверхности коренных зубов зверьков, собранных за относительно короткие промежутки времени (примерно две недели, ежемесячные выборки были поделены на две части - добытые в первую и во вторую половину месяца), довольно отчетливо группируются в несколько областей, разделенных перерывами. Эти группы значений индекса стертости принадлежат соответствующим возрастным классам.

Между возрастными классами 2+ и $3+, 3+$ и 4+ уже образуется хиатус. В течение всего периода исследований индекс стертости зубов 2-летних зверьков к концу лета не превышал $12.1 \%$, а у 3-летних он составлял $12.3 \%$ весной и $17.9 \%$ осенью. Зверьки возраста 4+ лет и более имели данный показатель не ниже 18.5 \%. Полученные нами данные по степени износа коронки коренных зубов в разных возрастных классах магаданской популяции бурундука сходны с таковыми в популяциях T. sibiricus Западной Сибири (Шубин, 1965). Некоторые отличия диапазона изменчивости этого показателя между бурундукамисеголетками Приохотья (0.6-3.5 \%) и Западной Сибири (0.1-5.0 \%), вероятно, связаны как с географическими особенностями питания, так и временем, проводимым молодыми зверьками с момента выхода из выводковой норы до залегания в спячку. В Западной Сибири сеголетки в массе появляются на поверхности в конце июня (Телегин, 1980; Шубин, 1991), т. е. на 2-3 недели раньше, чем в Северном Приохотье. Также и уходят они на зимовку примерно на 1.52 недели позднее. Более длительный период активного образа жизни, очевидно, приводит и к более сильному стиранию жевательной поверхности зубов. 
Таким образом, в условиях Северного Приохотья у перезимовавших зверьков на первом нижнем коренном зубе за летний сезон в среднем стирается около 5-6 \% жевательной поверхности, по крайней мере, в первые 34 года жизни. Для наглядности по средним значениям индекса стертости выделены «зубы-эталоны», отражающие различия между возрастными классами T. sibiricus (рис. 5).

На жевательной поверхности зубов взрослых зверьков, по сравнению с сеголетками, имеются значительные обнажения дентина. Эмаль в первую очередь стирается на бугорках и гребнях. При этом образуется рисунок из точек, запятых и узких полосок дентина, которые постепенно разрастаются и сливаются, формируя сначала полукольцо, а затем и широкое кольцо.

Полученные нами данные по воз-

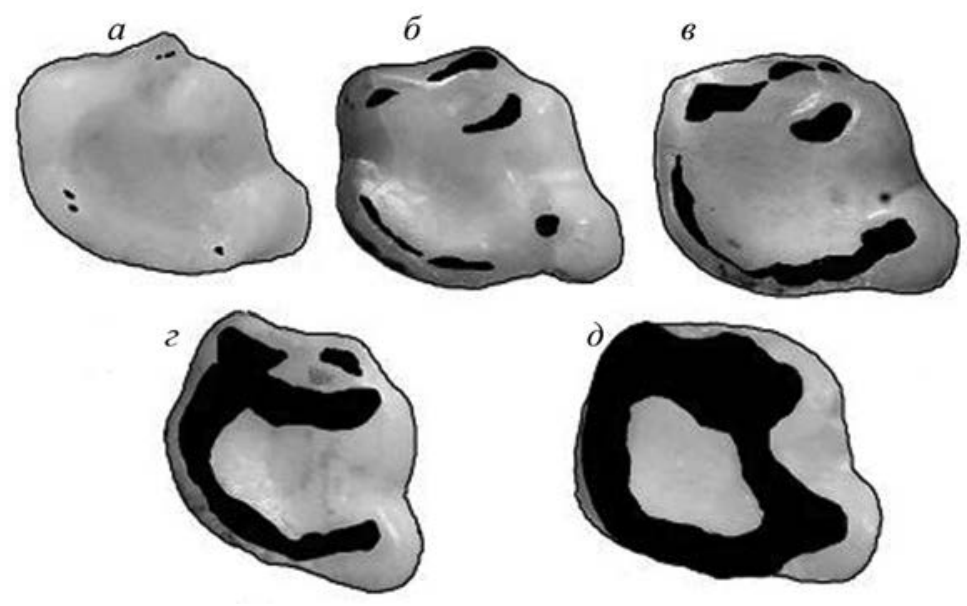

Puc. 5. Обнажения дентина на жевательной поверхности $m_{1}$ азиатского бурундука в возрасте: $a-0+, \sigma-1+, 6-2+, 2-3+, \partial-$ $4+$ лет и старше

Fig. 5. Dentin exposures on the $m_{1}$ masticatory surface of the Siberian chipmunk aged: $a-0+, \sigma-1+, b-2+, 2-3+, \partial-4+$ years and older растной изменчивости изношенности жевательной поверхности коренных зубов позволили определить возраст зверьков в исследуемой выборке. Материал, полученный за весь период работ с 2011 по 2014 г., был объединен для выявления обобщенной возрастной структуры популяции (табл. 2). Подобный прием дает возможность не только увеличить объем выборки, но и компенсировать случайные отклонения в изъятии отдельных возрастных классов в различные годы (Смирнов, 1983). Это, в свою очередь, позволяет получить более правильное представление о выживаемости и смертности отдельных возрастных классов в популяции.

Таблииа 2. Возрастная структура популяции Tamias sibiricus из окрестностей г. Магадана в 2011-2014 гг.

Table 2. Age structure of the Tamias sibiricus population from the surroundings of Magadan in 2011-2014

\begin{tabular}{|l|c|c|c|}
\hline $\begin{array}{c}\text { Возраст- } \\
\text { ная груп- } \\
\text { па, лет }\end{array}$ & $\begin{array}{c}\text { Индекс стертости } \\
\text { жевательной по- } \\
\text { верхности } m_{\nu}, \%\end{array}$ & $\begin{array}{c}\text { Количество } \\
\text { особей, } \\
\text { эк3. }\end{array}$ & $\begin{array}{c}\text { Доля } \\
\text { в выбор- } \\
\text { ке, \% }\end{array}$ \\
\hline $0+$ & $0.6-3.5$ & 36 & 20.7 \\
\hline $1+$ & $1.8-7.2$ & 71 & 40.8 \\
\hline $2+$ & $6.2-12.1$ & 44 & 25.3 \\
\hline $3+$ & $12.3-17.9$ & 18 & 10.3 \\
\hline$\geq 4+$ & $18.5-52.6$ & 5 & 2.9 \\
\hline
\end{tabular}

Основу популяции составляют годовалые зверьки (40.8 \%). До двух лет доживает в среднем $62 \%$ из них. Удельная выживаемость двухлетних особей не превышает 0.41. После трех лет смертность зверьков резко увеличивается, и до следующего года доживает менее четверти из них. Зверьки старше 4 лет встречаются единично, и для их разграничения по возрастным классам собранного материала недостаточно. Поэтому

определить максимальную продолжительность жизни бурундуков в условиях Северного Приохотья данным методом пока не представляется возможным. Единственный экземпляр в нашей выборке, имеющий значение индекса стертости жевательной поверхности моляра $52.6 \%$, мог достигать возраста 7-8-и лет. Подобная продолжительность жизни азиатского бурундука возможна в условиях неволи (Телегин, 1980), но в природе ранее не отмечалась, хотя известна для популяций некоторых видов американских бурундуков (Beg, Hoffmann, 1977).

В ходе каждого сезона размножения соотношение возрастных групп в популяции закономерно меняется. На протяжении первой половины летнего периода, с мая по середину июля, в ней преобладают зверьки возраста 1+. Их доля в среднем составляет $54 \%$. Далее, по мере появления на поверхности сеголеток, доминирование постепенно переходит к ним. Особенно это становится заметно в августе, когда доля молодых зверьков в популяции достигает 52-57 \%. Годовалых бурундуков в это время насчитывается всего 21-26 \%, а старше двух лет - 22-27 \%.

\section{ЗАКЛЮЧЕНИЕ}

В популяции бурундука Северного Приохотья индекс стертости жевательной поверхности первого нижнего коренного зуба в 2011-2014 гг. варьировал от 0.6 до $52.6 \%$. В выборках, полученных за короткие промежутки времени (23 недели), особи по индексу стертости распадаются на несколько хорошо различимых групп, соответствующих разным возрастным классам. У сеголеток изношенность жевательной поверхности $m_{l}$ составляет $0.6-3.5 \%$, у перезимовав- 
ших бурундуков она ежегодно увеличивается примерно на 5-6 \%. Но в связи с малым объемом выборки в старших возрастных классах уверенно определить возраст зверьков старше 4 лет (доля таких особей в популяции составляет 2.9 \%), а также максимальную продолжительность жизни не представляется возможным. Судя по величине индекса стертости, равного $52.6 \%$, этому зверьку могло быть 7-8 лет.

Доминирующим (40.8 \% от общей численности) возрастным классом в популяции бурундука Северного Приохотья является 1+. Выживаемость особей в возрасте от 1 до 3 лет равна примерно $50 \%$. После 3 лет она резко уменьшается, и до 4 лет и более доживает около $3 \%$ особей. В течение года возрастная структура популяции испытывает закономерные перестройки, сопровождающиеся сменой доминирующего возрастного класса. В первой половине летнего периода наиболее многочисленны особи в возрасте около 1 года, во второй половине лета доминирующей группой становятся сеголетки, доля которых в популяции достигает $52-57 \%$.

Пользуясь случаем, автор выражает свою глубокую благодарность С. В. Киселеву и А. В. Ямборко за предоставленный материал и А. Н. Субботиной за помощь в его обработке.

\section{ЛИТЕРАТУРА}

Докучаев Н. Е., Дубинин Е. А., Лазуткин А. Н., Иванов В. В., Грачев А. И. Млекопитающие // Растительный и животный мир заповедника «Магаданский». Магадан : СВНЦ ДВО РАН, 2011. С. 156-177.

Егоров О. В. Экология и промысел якутской белки. Москва : Изд-во АН СССР, 1961. 268 с.

Кирис И. Д. Методика и техника определения возраста и анализа возрастного состава популяции белки // Бюллетень Московского общества испытателей природы. Отдел биологии. 1937. Т. 46. Вып. 1. С. 36-42.
Кищинский А. А. Новые данные о распространении и биологии млекопитающих Колымского нагорья // Териология. Новосибирск : Наука, 1972. Т. 1. C. 192-205.

Клевезаль Г. А. Принципы и методы определения возраста млекопитающих. Москва : Наука, 2007. 283 с.

Машкин В. И., Колесников В. В. Определение возраста сурков (Marmota, Sciuridae) по рисунку стертости жевательной поверхности зубов // Зоологический журнал. 1990. Т. 69. Вып. 6. С. 124-131.

Меженный $A$. $A$. Методика определения возраста бурундука и анализ возрастного состава популяции в бассейне реки Олекмы // Позвоночные животные Якутии. Якутск : Кн. изд-во, 1964. С. 43-50.

Меженный $A$. A. Биология бурундука Южной Якутии // Материалы по биологии и динамике численности мелких млекопитающих Якутии. Якутск : Кн. издво, 1968. С. 87-119.

Новиков Г. А. Полевые исследования по экологии наземных позвоночных. Москва : Наука, 1953. 502 с.

Петровский Ю. Т. Особенности экологии крапчатского суслика в Белоруссии // Зоологический журнал. 1961. Т. 40. Вып. 5. С. 748-757.

Смирнов В. С. Принципы анализа возрастной структуры популяций по выборочным данным // Экология. 1983. № 1. С. 69-76.

Телегин В. И. Бурундук Западной Сибири. Новосибирск : Наука, 1980. 112 с.

Чернявский $\Phi$. Б. Млекопитающие крайнего северо-востока Сибири. Москва : Наука, 1984. 388 с.

Шадрина Е. Г. К методике определения возраста белки обыкновенной // Зоологический журнал. 1988. Т. 67. Вып. 8. С. 1229-1236.

Шубин Н. Г. К методике определения возраста бурундука // Ученые записки Томского государственного университета. 1965. № 51. С. 89-91.

Шубин Н. Г. Экология млекопитающих юго-востока Западной Сибири. Новосибирск : Наука, 1991. 263 с.

Юдин Б. С., Кривошеев В. Г., Беляев В. Г. Мелкие млекопитающие севера Дальнего Востока. Новосибирск : Наука, 1976. 270 с.

Beg M. A., Hoffmann R. S. Age determination and variation in the red-tailed chipmunk, Eutamias ruficaudus // Murrelet. 1977. Vol. 58. P. 26-36.

Поступила в редакциию 23.06.2021 2.

\section{AGE STRUCTURE OF THE SIBERIAN CHIPMUNK (TAMIAS SIBIRICUS) POPULATION IN THE NORTHERN PRIOKHOTYE}

\section{E. A. Dubinin}

\section{Institute of Biological Problems of the North, FEB RAS, Magadan}

The age-related variability of the abrasion degree of the masticatory surface of the first lower molar in the Northern Priokhotye population of the Siberian chipmunk has been studied. It has been revealed that, in young of the current year, from the time they abandoning breeding burrows to the hibernation period, the index of abrasion of the masticatory surface $m_{1}$ is $0.6-3.5 \%$. The area of exposed dentin on the molar masticatory surface increases annually by $5-6 \%$ averagely in overwintered adult animals. According to the abrasion index, 4-5 age classes are distinguished in the population. The group of animals aged $1+$ yrs dominates in number $(40.8 \%)$. The specific survival rate of individuals in the range from 1 to 3 years is approximately 0.5 . After three years, it drops sharply $(0.23)$. Less than $3 \%$ of individuals survive up to 4 years or more in the population. 


\section{REFERENCES}

Beg, M. A., Hoffmann, R. S., 1977. Age Determination and Variation in the Red-Tailed Chipmunk, Eutamias ruficaudus, Murrelet. 58, 26-36.

Chernyavsky, F. B., 1984. Mammals of the Far NorthEast of Siberia. Moscow, Nauka [In Russian].

Dokuchayev, N. E., Dubinin, E. A., Lazutkin, A. N., Ivanov, V. V., Grachyov, A. I., 2011. Mammals, Flora and Fauna of the Magadansky Reserve. Magadan, NESC FEB RAS. 156-177 [In Russian].

Kiris, I. D., 1937. Methodology and Technique for Determining the Age and Age Composition Analysis of the Squirrel Population, Bulletin of Moscow Society of Naturalists. Biological Series. 46 (1), 36-42 [In Russian].

Kishchinsky, A. A., 1972. New Data on the Distribution and Biology of Mammals in the Kolyma Upland, Teriologiya. Novosibirsk, Nauka. 1, 192-205 [In Russian].

Klevezal, G. A., 2007. Principles and Methods for Determining the Age of Mammals. Moscow, Nauka [In Russian].

Mashkin, V. I., Kolesnikov, V. V., 1990. Marmots (Marmota, Sciuridae) Age Determination by the Pattern of Abrasion of the Teeth Chewing Surface, Zoologicheskii Zhurnal. 69 (6), 124-131 [In Russian].

Mezhenny, A. A., 1964. Methodology for Determining the Chipmunk Age and the Age Composition Analysis for the Population in the Olyokma River Basin, Vertebrates of Yakutia. Yakutsk. 43-50 [In Russian].
Mezhenny, A. A., 1968. Biology of the Chipmunk in South Yakutia, Material on the Biology and Number Dynamics of the Small Mammals in Yakutia. Yakutsk. 87119 [In Russian].

Novikov, G. A., 1953. Field Study on the Ecology of Terrestrial Vertebrates. Moscow, Nauka [In Russian].

Petrovsky Yu. T., 1961. Features of the Ecology of the Speckled Ground Squirrel in Byelorussia, Zoologicheskii Zhurnal. 40 (5), 748-757 [In Russian].

Shadrina, E. G., 1988. On the Methodology of Age Determination for the Common Squirrel, Zoologicheskii Zhurnal. 67 (8), 1229-1236 [In Russian].

Shubin, N. G., 1965. On the Methodology of the Age Determination for the Chipmunk, Uchyoniye Zapiski Tomskogo Gosudarstvennogo Universiteta. 51, 89-91 [In Russian].

Shubin, N. G., 1991. Ecology of Mammals in the SouthEast of West Siberia. Novosibirsk, Nauka [In Russian].

Smirnov, V. S.,1983. Principles of the Population Age Structure Analysis by Selected Data, Russian Journal of Ecology. 1, 69-76 [In Russian].

Telegin, V. I., 1980. The Chipmunk in West Siberia. Novosibirsk, Nauka [In Russian].

Yegorov, O. V., 1961. Ecology and Hunting for the Yakut Squirrel. Moscow, AN USSR [In Russian].

Yudin, B. S., Krivosheyev, V. G., Belyaev, V. G., 1976. Small Mammals in the North of the Far East. Novosibirsk, Nauka [In Russian]. 